\title{
The Role of the Students in the CLIL Classroom A New Perspective to Identify Types of Tasks
}

\author{
David González Gándara \\ University of Santiago de Compostela, Avda. De Castelao s/n. Campus Norte. 15782 Santiago de Compostela, Spain \\ E-mail: david.gonzalez.gandara@rai.usc.es
}

Received: 14-11-2016

Accepted: 19-01-2017

Published: 01-07-2017 doi:10.7575/aiac.ijalel.v.6n.4p.5

Advance Access Published: April 2017

URL: http://dx.doi.org/10.7575/aiac.ijalel.v.6n.4p.5

\begin{abstract}
A good deal of authors have spotted the crucial factors to get into account in order to classify tasks for their study. Although the role of the student in the task has been studied before, it has not been considered as a key factor in some of the most influential models. I propose a new perspective to describe it. It consists in a combination of the participation of the students in the input of tasks and their participation in the output. A case study has been carried out to address the statistical effects of the factor proposed in two variables: the amount of As-units (Foster, Tonkyn, \& Wigglesworth, 2000) in the L2 produced in the classroom, and among them, the amount of initiating moves (Leech \& Weisser, 2003). Transcripts of the audio and video recordings taken during eight CLIL Science lessons taught to an intact class of ten students of grades 1 and 2 were analysed. The results showed that the role of the students in the input had a significant effect on the variables measured. The teacher produced more As-units in general and initiating moves in particular, while the students produced less As-units while still producing more initiating moves.
\end{abstract}

Keywords: Input, Second Language Acquisition, Task, Bilingual Education, CLIL, role

\section{Introduction}

The study of tasks in Second Language Acquisition has attracted the scholars' attention for long. Google Scholar throws almost 2,510,000 results for the search "Second Language Acquisition task" (1,417 in EBSCO). Adding the term "CLIL" to the search, the amount of articles is reduced, but there are still more than 7,000 (4 in EBSCO). However, there is not a standard to classify tasks, although some of them have become very influential (Prabhu, 1987; Robinson, 2007). I introduce a new way to measure the role of the student in the tasks trying to address an important factor that explains the differences in performance in the L2 by the students and the teacher so that this factor can be incorporated in task taxonomies.

Firstly, I will try to establish what a task is. They have been frequently defined in the literature. Sometimes the term is used as a general word to refer to activities in educational contexts. Some other times, on the contrary, they are clearly distinguished from other kind of activities. Especially in the case of authors who write about task-based learning. The following definitions have been widely accepted.

$[\ldots]$ a task is an activity in which:

- meaning is primary;

- there is some communication problem to solve;

- there is some sort of relationship to comparable real-world activities;

- task completion has some priority;

- the assessment of the task is in terms of outcome. (Skehan, 1998, p. 95)

The term "task" is sometimes used with the same generic meaning as "activity"[...]

My own narrower definition of task is based on four key criteria:

1. The primary focus should be on "meaning" (by which I mean learners should be mainly concerned with processing the semantic and pragmatic meaning of utterances).

2. There should be some kind of "gap" (i.e. a need to convey information, to express an opinion or to infer meaning).

3. Learners should largely have to rely on their own resources (linguistic and non-linguistic) in order to complete the activity.

4. There is a clearly defined outcome other than the use of language (i.e. the language serves as the means for achieving the outcome, not as an end in its own right). (Ellis, 1984, p. 198) 
In order to study tasks for research, some elements can be identified. The first one is the input, provided mainly by the teacher with the help of some resources. Another one is the output, produced by the students when they perform some activities. The job of a good teacher is to make the right decisions about the input and the activities. If the output he or she gets is not the expected, something should be changed. There are a lot of other circumstances around tasks that can influence them (the type of activities included, the style of communication, etc.) . Sometimes authors also take them into account when they establish a classification.

\section{Literature Review}

Robinson (2007, p. 7) described in depth the different approaches existing for task classification: behaviour descriptive, information-theoretic and ability requirements. He also defines the conditions for a task taxonomy to comply in order to be useful. Firstly, it has to be empirically researchable. Secondly, it should be operationally feasible, permitting classification and design of a wide range of pedagogic tasks reliably and consistently, by researchers and teachers.

He defines three dimensions: cognitive factors, interactive factors and learner factors. Then he adds several indicators for each factor. In later papers he develops a longer list of dimensions for each of the factors (Robinson \& Gilabert, 2007, p. 164). Some of the dimensions he defines for each factor are the following.

Tasks Complexity (Cognitive factors) +/- here and now; +/- few elements; -/+ spatial reasoning; -/+ causal reasoning; +/- planning time; + /- few steps; + /- prior knowledge; etc.

Task condition (Interactive factors) +/- open solution; +/- one-way flow; +/- few participants; +/- negotiation not needed; etc.

Task difficulty (Leaner factors) h/l working memory; h/l reasoning; h/l task motivation; h/l self-efficacy

I agree with some features of Robinson's model, but it becomes too complicated for the teachers with so many indicators. When they are too many, it is also difficult to do research because the data analysis becomes too complicated. Most of the research I found (Robinson, 2001, 2005, Robinson \& Gilabert, 2007, Robinson, 2007) centres on one or two of them. The most usual factors to study are the task complexity and the here-and-now factors.

Another very influential model is the one proposed by Cummins (2000). This model uses only two dimensions: the cognitive demand and the context support. These two dimensions are clearly parallel to the complexity and the hereand-now.

Tavakoli and Foster (2011, p. 445) mention a couple of studies (Skehan \& Foster, 1997, Foster \& Skehan, 1996) which analyse the familiarity of the content as a concretion of cognitive complexity. They claim that talking about oneself and one's life leads to higher measures of accuracy and fluency, while unfamiliar information leads to less accurate and less fluent performance. In my opinion, the familiarity with the content is more closely related with the idea of context than with the idea of cognitive complexity.

Salaberri (1999, p. 154) observed that other ways of classifying the tasks do not really make that difference in terms of L2 use. She does find that difference when analysing "the student being familiar". Surprisingly, she does not consider that as a criterion for task classification.

However, relationship with the type of task was not significant, which indicates that teachers tend to promote turn taking similarly with regards to all tasks, without this being a influential variable. (Salaberri, 1999 , p. 154)

Ellis (2009) focuses on the effects of task planning in performance. Task planning is not part of the task itself, it falls in the domain of the teaching approach. The author finds task planning to have an effect on performance, but it is not a factor that should be included in a classification of tasks.

Nunan (1989) suggests that only three components of the task are necessary to analyse them: the objectives, the input and the activities.

Other authors use a wider variety of elements for a deeper analysis of tasks. For instance, Coyle, Hood, and Marsh (2010) enumerate only a few: the nature of the information, the output formats, language requirements, how much thinking is needed, etc. Prabhu (1987) also mentions some of them when referring to the Bangalore Project.

After the analysis of the most influential taxonomies used in research, it is clear that the role of the student in the tasks has not taken a lot of attention by researchers.

\section{A new perspective for the role of the student in a task}

Commonly, when the role of the student in the task is analysed (Nunan, 1989), what is observed is the nature of the interaction. For instance, if the communication model follows a student-student way, a student-teacher, a teacherstudent, and so on. Or also, the time available for the students to participate. An example of this is the list by Skehan (1998).

3. Communicative stress

- time limits and time pressure

- speed of presentation

- number of participants

- length of texts used

- type of response

- opportunities to control interaction. (Skehan, 1998) 
The information gap has also been studied (Doughty \& Pica, 1986). "Information gap refers to the existence of a lack of information among participants working on a common problem, but the term does not define the nature of the gap". Prabhu (1987) also uses this idea as key for a classification of tasks. One of the kinds of the information gap occurs when some of the students have a bit of information that the others need.

In this paper I propose a new perspective to approach the study of the input in the tasks. According to the information gap idea, the new concept is defined as "the amount of input that is provided from the students themselves, that is, that some students use some information that comes from other students". I will call it role of the student in the task.

The new concept is different to the previously studied information gap. Firstly, the information received from the students is not necessarily needed in order to complete the task, as opposed to the definition of information gap. Furthermore, the role of the student in the task combines the participation in the input and the participation in the output. This latter is not considered at all in the idea of information gap. When the students are producing an output in the task, it is at the same time input for the rest of the students, who can use this information for several purposes. They can even interact with this input.

For example, in a board game, they need to understand what the other children say because they need that information for the strategy of the game, and to check that they are not cheating. They could, nevertheless, not use this information, and keep with the game. A different example would be the dictation of a picture by a student. In this case they just cannot complete the activity without the information they are going to receive from the student who dictates.

In other activities such as interviewing the language assistant, they do not need information from the other students' utterances. As for songs, students sometimes can play the role of participants in the input, when some students that do not know the words follow the ones that do. That is, the aim of the task is to perform the task, and in order to do that, they repeat what they hear from other students. So the input they use to perform the song came from the students, not the teacher. To my knowledge, the use of this concept as a dimension to differentiate tasks is new in task-based CLIL research.

The activities described above would have different measures with regards to role of the students in the task. Table 1 summarises the main points to take into account to measure this dimension. The participation of the students in the input, as I said, is given more weight, provided teachers typically dominate the talk in the classroom (Ellis, 1997). A task can be considered as a high role task if it gets, for instance, 5 points from the table. This is only an example of how the role can be measured. It is important to consider the numbers only as a tool and not as a rigorous rule. Each teacher or researcher might build his or her own table, or any other way of assessment according to the idea.

Table 1. The role of the student in the tasks

\begin{tabular}{l|l|l|l}
\hline \multicolumn{2}{|c|}{ Participation in the input } & Participation in the output \\
\hline 0 & $\begin{array}{l}\text { No participation. All the input is } \\
\text { provided by the teacher, either } \\
\text { directly or indirectly (audiovisual } \\
\text { materials, etc.) }\end{array}$ & $\begin{array}{l}\text { Output from the students is not } \\
\text { expected. }\end{array}$ \\
\hline 2 & $\begin{array}{l}\text { Most of the input comes from the } \\
\text { teacher. }\end{array}$ & 1 & Output strongly guided. \\
\hline 4 & $\begin{array}{l}\text { Most of the input comes from the } \\
\text { students. }\end{array}$ & Slightly guided output. \\
\hline 6 & All the input comes from the students. & 3 & $\begin{array}{l}\text { Free output (no help from templates } \\
\text { or the teacher). }\end{array}$ \\
\hline
\end{tabular}

\section{Method}

A case study was carried out in order to verify that the new way of interpreting the role of the students in a task, measured according to table 1 , is a good candidate as a dimension for a taxonomy of tasks.

\subsection{Hypothesis}

The hypothesis of the experiment is: "the amount of L2 produced in the classroom as well as its quality is going to be positively affected when tasks are planned expecting a high participation of the students". Provided an effect of the role of the students in the task factor was observed in the variables measured, this factor would have been proven to be a good defining factor for tasks.

\subsection{Participants}

Ten students from grade one and two in an Elementary rural school in Galicia (Spain) participated in this case study. They are the whole group of class, no subset was selected for the experiment. These are the natural conditions for this classroom. They study in a trilingual program, with around a third of the schooling time in Spanish, the third in Galician and the other third in English. Apart from the language subjects, they also have content subjects in the three languages. In the case of the L2 (English), this subjects are Science and Art. All the students have studied English as a subject in kindergarten. In the case of the grade 2 students they also studied Science and Art in English in grade 1. 


\subsection{Collection of Data}

After randomly recording some Science lessons taught in English, eight task-episodes where selected according with the criteria of having examples of the two levels, namely high and low, of the role factor. These recordings where transcribed and labeled in order to quantify the number of As-units (Foster, Tonkyn, \& Wigglesworth, 2000, p. 365) (note 1) produced in the L2, and among them, the number of instances of an initiating communicative function (Leech \& Weisser, 2003, p. 4-5). A unit has an initiating function when it starts a communication move. Examples are: questions, requests, etc.

I chose the initiating moves as an indicator of L2 quality. It is much harder for students to initiate moves than only responding to the moves initiated by the teacher. All these variables where measured against the amount of L2 produced, in As-units per second. I did not use the common complexity, accuracy and fluency because they are not useful when referring to young learners. Their language is too simple to use those measures, consisting in many cases in mere one-word sentences.

\subsection{Analysis}

After the collection of the data, the program $R$ was used to create the figures and observe the effects of the variables. The variables were measured in the different experimental conditions. The conditions observed were tasks with a high role and tasks with a low role. The same group of students was observed for all the conditions. Given the size of the sample, and the nature of case studies in general, mathematical analysis of the variance would not reinforce the interpretation of the data.

\section{Results and discussion}

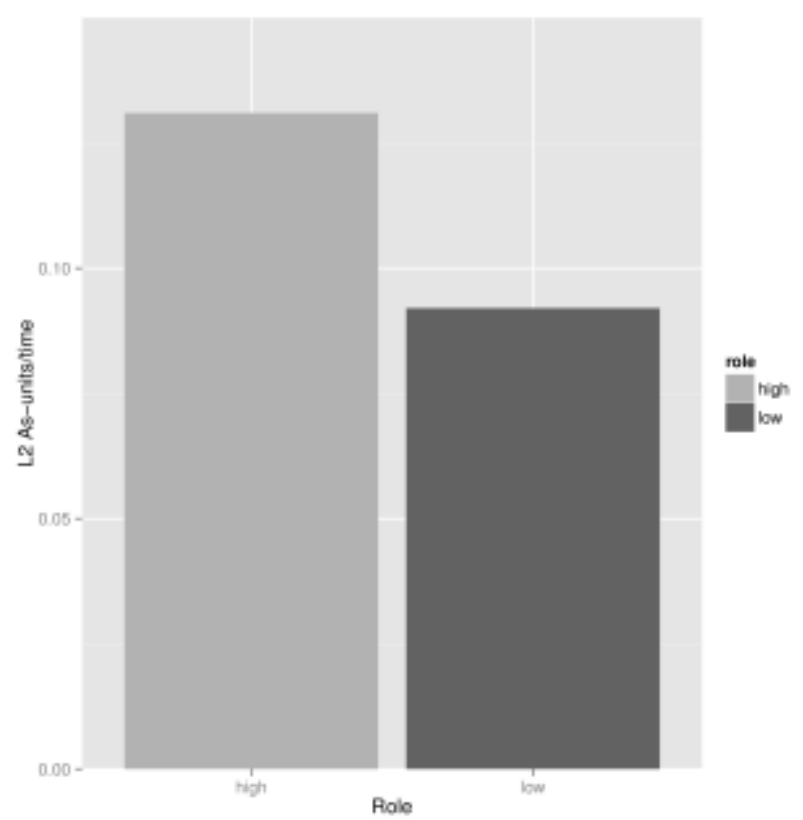

[a. Teachers: quantity of spoken L2 according to role]

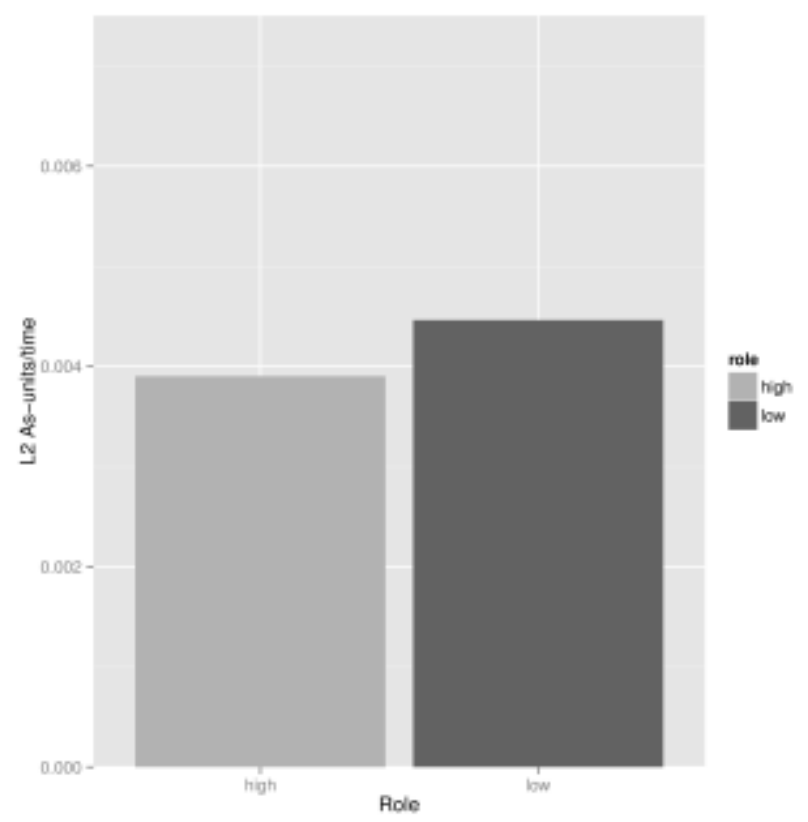

[b. Students: quantity of spoken L2 according to role]

Figure 1. Results of quantity of L2 for students and teachers

The analysis of the data shows that the difference in the amount of L2 production by the students according to the role is really significant, being the episodes with a lower influence of the students in the task those with a higher amount of L2 produced by them. Figure $1 \mathrm{~b}$ shows this.

As for the linguistic functions, it is clear from figure 2 that the factor role is clearly related with the students producing more initiating As-units.

I found these results very surprising. I was expecting to get clear results that the role would determine a lot the amount of L2 the students produced, but in fact it undermines it (see figure 1b). The higher the participation of the students in the input of the task, the less number of As-units was produced. This is partially explained because of the fact that the production of the students in the L2 is really scarce (Krashen, 1998). It may be so little that the differences can not get really significant.

Although the concept of information gap is slightly different, it is similar enough to compare the results of this study with the one carried out by Doughty \& Pica (1986). This is study is not recent, but to my knowledge, current research is not addressing this kind of dimension of tasks. It is mainly focused in the task complexity, or the here-and-now (Robinson, 2001, 2005; Robinson \& Gilabert, 2007; Robinson, 2007; Tavaloky \& Foster, 2011; Tardieu \& Doltisky, 
2012). They compared teacher-fronted tasks with group participation with regards to the total amount of interaction (note 2).

There was more total interaction produced in the teacher-fronted pattern than in the group in both types of task ...

In itself, this finding is not particularly astonishing. After all, teachers do tend to talk a great deal, speak more quickly, and

hesitate less often in comparison with ESL students struggling to

learn a new language. Thus, their fluent native speech would add to

the total amount of interaction. (Doughty \& Pica, 1986, p. 320)

This goes in the same line as the findings in the present paper. The explanation that these authors give for the phenomenon observed could also fit with my findings. Even when it is contradictory, planning tasks to have a lower role of students can in fact increase the amount of L2 that they produce.

In the case of the teachers, however, the results were as expected. They produced more English in those episodes with a higher "role" of the students (see figure 1a).

Regarding the effect of the role factor in the communicative functions produced by the students, they were according to the expectations. The initiating As-units where in fact non-existent in the episodes labelled with low role (see figure 2). This is very significant, because the educational objectives of language teaching usually foster that the students can initiate the linguistic exchanges in an active role.

Establishing a relationship between the different facts observed, we can see that although the task-episodes with lower values of role were those with a higher number of As-units produced, most of these As-units were not initiating Asunits. That is to say, it seems that apart from favouring the production of L2 by the teachers, increasing the role of the students in the task also favours the richness of the students communication in the L2. Again, this has to be confirmed by further research.

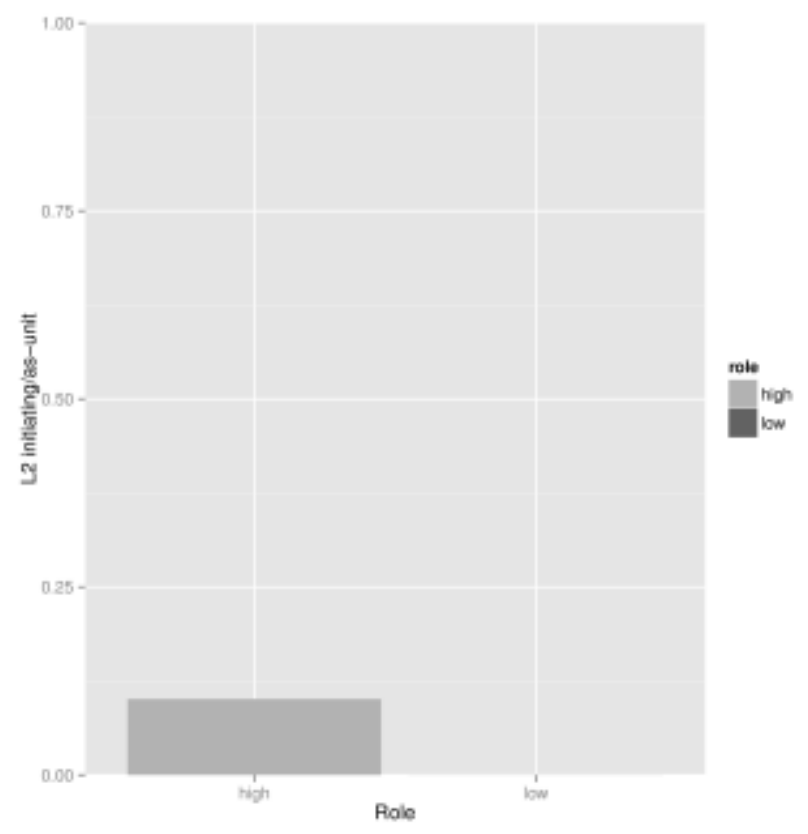

Figure 2. Results of initiating acts for students

\section{Conclusion}

After the analysis of the data, I can say that this new perspective to observe the role of the students in tasks is a good candidate for a factor in a taxonomy of tasks. They can be classified into two categories: tasks with a high role of the students and tasks with a low role of the students. This factor could be combined with others to create more categories. The rest of the factors should be found according to statistical effects confirmed in research studies. Other good candidates, as described in the introduction could be related with the here-and-now of the task, or with the task complexity. These two dimensions of tasks have been widely selected by scholars for their research about tasks. According to Robinson and Gilabert (2007), a good taxonomy would probably have three factors. I agree with this view, and I propose the following three: the role of the student in the task, the task complexity and the here-and-now.

Even though the case studied showed a clear effect of the new dimension role of the student in the task, further research in other classes and different contexts is needed in order to confirm what has been found in this initial study. 


\section{References}

Coyle, D., Hood, P., \& Marsh, D. (2010). Content and language integrated learning. Ernst Klett Sprachen.

Cummins, J. (2000). Language, power, and pedagogy: Bilingual children in the crossfire (Vol. 23). Multilingual Matters. https://doi.org/10.1080/15235882.2001.10162800

Tardieu, Claire \& Doltisky, Marlene (2012). Integrating the task-based approach to CLIL teaching, in J. de Dios (coord.), Teaching and Learning English through Bilingual Education, Cambridge Scholars Publishing, 2012, pp. 3-35.

Doughty, C., \& Pica, T. (1986). "Information gap" tasks: Do they facilitate second language acquisition? TESOL QUARTERLY, 20 (2), 305-323. https://doi.org/10.2307/3586546

Ellis, R. (1984). Classroom second language development: A study of classroom interaction and language acquisition. Pergamon.

Ellis, R. (1997). SLA research and language teaching. ERIC.

Ellis, R. (2009). The differential effects of three types of task planning on the fluency, complexity, and accuracy in L2 oral production. Applied Linguistics. https://doi.org/10.1093/applin/amp042

Foster, P., \& Skehan, P. (1996). The influence of planning and task type on second language performance. Studies in Second language acquisition, 18 (03), 299-323. https://doi.org/10.1017/s0272263100015047

Foster, P., Tonkyn, A., \& Wigglesworth, G. (2000). Measuring spoken language: A unit for all reasons. Applied Linguistics, 21 , 354-375. https://doi.org/10.1093/applin/21.3.354

Krashen, S. D. (1998). Comprehensible output? System, 26 , 175-182. https://doi.org/10.1016/s0346-251x(98)00002-5

Leech, G., \& Weisser, M. (2003). Generic speech act annotation for task-oriented dialogue. In D. Archer, P. Rayson, A. Wilson, \& A. McEnery (Eds.), Proceedings of the corpus linguistics 2003 conference. Lancaster: UCREL Technical Papers. https://doi.org/10.3115/1118078.1118084

Nunan, D. (1989). Designing tasks for the communicative classroom. Cambridge University Press. https://doi.org/10.1017/s0272263100009578

Prabhu, N. S. (1987). Second language pedagogy (Vol. 20). Oxford University Press Oxford.

Robinson, P. (2001). Task complexity, task difficulty, and task production: Exploring interactions in a componential framework. Applied linguistics, 22 (1), 27-57. https://doi.org/10.1093/applin/22.1.27

Robinson, P. (2005). Cognitive complexity and task sequencing: Studies in a compo nential framework for second language task design. International Review of Applied Linguistics, 43 , 1-32. https://doi.org/10.1515/iral.2005.43.1.1

Robinson, P. (2007). Criteria for classifying and sequencing pedagogic tasks. Investigating tasks in formal language learning, 7-26.

Robinson, P., \& Gilabert, R. (2007). Task complexity, the cognition hypothesis and second learning and performance. International Review of Applied Linguistics, 45 , 161-176.

Salaberri, S. (1999). El discurso del profesor en el aula y su relación con las tareas de aprendizaje. Universidad de Almería.

Skehan, P. (1998). A cognitive approach to language learning. Oxford University Press.

Skehan, P., \& Foster, P. (1997). Task type and task processing conditions as influences on foreign language performance. Language Teaching Research, 1 (3), 185-211. https://doi.org/10.1177/136216889700100302

Tavakoli, P., \& Foster, P. (2011). Task design and second language performance: The effect of narrative type on learner output. Language Learning, 61 (s1), 37-72. https://doi.org/10.1111/j.1467-9922.2011.00642.x

\section{Notes}

Note 1. The Analysis of Speech Unit (As-unit) is a single speaker's utterance consisting of an independent clause, or subclausal unit, together with any subordinate clause(s) associated with either. 